\title{
The Impact of Government Policies on the Growth and Development of SMEs interprises in Bauchi State Nigeria
}

https://doi.org/10.21272/sec.5(2).111-119.2021.

Yakubu Yahaya, ORCID: https://orcid.org/0000-0002-9268-3130

Senior Lecturer, Department of Business Administration and Management, School of Management Sciences, Abubakar Tatari Ali Polytechnic Bauchi, Bauchi state, Nigeria

Umar Ayuba Dutse, ORCID: https://orcid.org/0000-0003-4488-0321

Senior Lecturer, Department of Business Administration and Management,Abubakar Tatari Ali Polytechnic Bauchi, Bauchi state, Nigeria

Sule Bello, ORCID: https:/orcid.org/0000-0003-1045-8501

Lecturer I, Department of Business Administration and Management, School of Management Sciences, Abubakar Tatari Ali Polytechnic Bauchi, Bauchi state, Nigeria

\begin{abstract}
Every business or start-up was e-ray by the government official ranging from local, state and federal level in Nigeria. Therefore, for SMEs to operate it's a perquisite to follow the due process from registration by ministry of commerce and industry at state level and the various agencies responsible for registration. This challenge represents both widespread personal misfortune for individuals and a lost opportunity for critical national and global economic development. This study examines the challenges that affect the growth and development of small and medium enterprises in Bauchi state, Nigeria .The study was guided by an epistemological research philosophy adopting a positivist research paradigm. The research design was cross-sectional survey design using both quantitative and qualitative approaches. The target population for this study was 754 registered small and medium scale owned enterprises registered with the Bauchi state government by December 2019 and the sample size was 172 respondents derived using Fisher's formulae. This study used a self-administered, closed, and openended questionnaire to obtain quantitative data. The study used descriptive statistics such as mean, standard deviation, median and proportions using the Statistical Package for Social Sciences (SPSS) version 24 and Microsoft Excel. Regression analysis and correlation analysis were used to determine the direction and strength of the relationship between the independent and the dependent variables.. The questionnaires were administered among the seventy (70) management staff members of the one hundred and seventy two (172) selected SMEs in Bauchi state Nigeria through purposive sampling method, and this was done personally by the researcher. Descriptive and inferential statistics was use to analyze and interpret the data use in this research. The study reveals that government policies is a major challenges that help SMEs to grow and achieve its stated objectives in global competitive environment. On same vain this study is so keen and motivated to established evidence on these challenges ascertain especially, in a context of current phenomena SMEs face in Bauchi state. Finally, the study will utilize the element of contingency theory, as these SMEs require sound institutional framework to mitigate these challenges. However, anecdotal evidence shows that SMEs in developing countries like Nigeria are faced with a lot of challenges that have hampered their growth in recent times. Among these challenges are: intermittent power supply, indiscriminate tax levies government policy, low accessibility to loans from financial institutions and inability to keep proper financial records. The study reveals that Government policies have a significant impact on the growth and development of SMEs in Bauchi State, Nigeria. Subsequently, the study recommends that management of SMEs should adopt good strategy in order to overcome these challenges.
\end{abstract}

Keywords: government policies, growth and development, challenges, SMEs.

JEL Classification: M13, M19. 
Cite as: Yahaya, Ya., Dutse, U.A., Bello, S. (2021). The Impact of Government Policies on the Growth and Development of SMEs interprises in Bauchi State Nigeria. SocioEconomic Challenges, 5(2), 111-119. https://doi.org/10.21272/sec.5(2).111-119.2021.

Received: 28.04 .2021

Accepted: 29.05 .2021

Published: 25.06 .2021

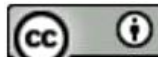

Copyright: (C) 2021 by the author. Licensee Sumy State University, Ukraine. This article is an open access article distributed under the terms and conditions of the Creative Commons Attribution (CC BY) license (https:// creativecommons.org/licenses/by/4.0/).

\section{Introduction}

A challenge affecting Small and medium enterprise has become a recognized phenomenon all over the world despite being the veritable catalyst for economic growth and development. The history of industrial revolution and empirical studies have shown that the sub - sector had contributed immensely to the development process of both the developed and the developing world though non - formal employment generation, production of intermediate goods and services, pre industrial entrepreneurship and technology incubation. This challenge represents both widespread personal misfortune for individuals and a lost opportunity for critical national and global economic development. The challenge has been shown to have lifelong effects on income, employment stability and slow development because it affects economic confidence and resilience to self employment capacity.

United Nations "World Youth Report",( 2012)The recent economic crisis has had a disproportionate - and disproportionately long-term - effect on growth and development. Today SME's has been recognizing as a civilizing influence which enrich the lives of men and women, and thereby regarded as a developmental strategy which reverses our economic downward trends. An expensive list of benefit has inspired the adoption of policies relates SME's policies that reflects efficient factor utilization, employment generation, innovative industrialization and democratization of capital formation regional development, poverty alleviation etc. Based on its impact on economic development SME's also received a greater attention now than ever before on this current political dispensation in most underdevelopment countries especially African states. On same vain this study is so keen and motivated to established evidence on these challenges ascertain especially, in a context of current phenomena SMEs face in Bauchi state. Finally, the study will utilize the element of contingency theory, as these SMEs require sound institutional framework to mitigate these challenges.

However, anecdotal evidence shows that SMEs in developing countries like Nigeria are faced with many challenges that have hampered their growth in recent times. Among these challenges are: intermittent power supply, indiscriminate tax levies, low accessibility to loans from financial institutions and inability to keep proper financial records. Oluboba (2010) opined that the main problems facing SMEs, which are however not unsurmountable are: low level of entrepreneurial skills, poor management practices, low access to money and capital markets, low equity participation from the promoters because of insufficient personal savings due to their level of poverty and low return on investment, inadequate equity capital, poor infrastructural facilities, high rate of enterprise mortality, shortages of skilled manpower, multiplicity of regulatory agencies and overbearing operating environment, societal and attitudinal problems, integrity and transparency problems, restricted market access, lack of skills in international trade; bureaucracy, lack of access to information given that it is costly, time consuming and complicated at times. In the same vein Onugu (2010) asserts that the major challenges facing SMEs include; insufficient capital, lack of focus, inadequate market research, overconcentration on one or two markets for finished products, lack of succession plan, inexperience, lack of proper book keeping, lack of proper records or lack of any records at all, inability to separate business and family or personal finances, lack of business strategy, inability to distinguish between revenue and profit, inability to procure the right plant and machinery, inability to engage or employ the right caliber of staff, painlessness, cut-throat competition, lack of official patronage of locally produced goods and services, dumping of foreign goods and over-concentration of decision making on one (key) person, usually the owner. Other challenges which SMEs face in Nigeria include irregular power supply and other infrastructural inadequacies. unfavorable fiscal policies, multiple taxes, levies and rates, 
fuel crises or shortage, policy inconsistencies, reversals and shocks, uneasy access to funding, poor policy implementation, restricted market access, raw materials sourcing problems, competition with cheaper imported products, problems of inter-sectorial linkages given that most large scale firms source some of their raw material outside instead of sub-contracting to SMEs, insecurity of people and property, fragile ownership base, lack of requisite skill and experience, thin management, unfavorable monetary policies, lack of preservation, processing and storage technology and facilities, lack of entrepreneurial spirit, poor capital structuring as well as poor management of financial, human and other resources. Osoba (1987) and Innag and Ukpong (1993) opine that financial institutions classify loans disbursed to small and medium scale enterprises as "high risked loans".

\subsection{General Objective}

The general objective of the study is to determine the impact of government policies on the growth and development of SMEs in Bauchi State, Nigeria

\subsubsection{The specific objective;:}

1. To ascertain the impact of government policies on the growth and development of SMEs in Bauchi state, Nigeria

\subsection{Research Questions}

1. Does government policies on raw materials affect the growth and development of SMEs in Bauchi state Nigeria?

\subsection{Research Hypothesis:}

$\mathbf{H}_{02}$ Government policies have no significant impact on the growth and development of SMEs in Bauchi State, Nigeria.

\section{Statement of the problem}

Small and Medium Enterprises (SMEs) in Nigeria have not performed creditably well and hence have not played the expected vital and vibrant role in the economic growth and development of Nigeria. Olayemi (2016) posits that most SMEs in Bauchi state die within their first five years of existence, a smaller percentage goes into extinction between the sixth and tenth year while only about five to ten percent survive, thrive and grow to maturity due harsh government policies. Many factors have been identified contributing to this premature death of SMEs. Key among them include: insufficient capital, irregular, infrastructural inadequacies, lack of managerial skills, inadequate market research, over-concentration on one or two markets for finished products, lack of succession plan, inexperience, lack of proper book keeping, lack of proper records or lack of any records at all, inability to separate business and family or personal finances, lack of business strategy, inability to distinguish between revenue and profit, inability to procure the right plant and machinery, inability to engage or employ the right caliber of staff, cut-throat competition Stem and Barbour (2015].

Beckman, (2017) contend that most of the problems of SMEs are external to it, among them are those related to capital shortage, taxation and regulations, product liability patent and franchising abuses. The internal problems of SMEs in Nigeria include: inadequate working capital, stiff competition from larger companies, difficulties in sourcing raw materials, low capacity utilization, lack of management strategies, poor educational background of operators, and huge financial problems while the external problems include: policy inconsistencies, multiple taxation, harsh regulatory requirements and trade groups. It is also important to note that SMEs in Bauchi state are not immune from the aforementioned challenges in their day to day operations hence it becomes necessary to embark on a study that investigates the challenges that affects the growth and development of SMEs in Bauchi State, Nigeria

\section{Justification of the study}

This study tend to justify the needs for detail to enable the management of SMEs in Bauchi State, Nigeria to understand the strategic ways of overcoming some of the challenges facing SMEs growth and development in 
Bauchi state and further shed more light on how they can optimize on it to gain and retain competitive advantage in today's turbulent business environment. The findings of this study would eventually provide insight and new knowledge for the stakeholders in manufacturing sector. The findings provided necessary information on how to successfully manage SMEs in Nigeria. The stakeholders and management of SMEs may further adopt the findings of this study so to improve the performance of their companies. The study would also contribute to the existing literature in the field of SMEs of management for the banking sectors in Nigeria. It should also act as a stimulus for further research to refine and extend the present study especially in Bauchi and Nigeria at large.

\section{Literature Review}

\subsection{Concept of Small and Medium Enterprises (SMEs)}

What is this concept SMEs all about? There is no single definition of the concept so far certain variables and parameters were used to define the concept like capital base, number of employment and assets to mention but a few. For example the European Union define Medium enterprise as an entity that poses about 250 employees and small enterprise has about less than 50 and the lesser on the called micro has a maximum of 10 employees with around 40milllion or less turnover or it has a balance sheet value of not above 27 million euro. United State and Canada has almost similar criteria with less than 50 employees indicates large business and less 100 employees in product - based and less than 50 employees in service -based business (Industry Canada, 2005). In eastern African countries for example Tanzani Micro indicates 1-4 employees and capital base of up to 5 million Tanzanian shillings, small business accounts for 5- 49 employees and capital of above 5-200 million Tanzanian shillings, medium business clock about 50- 99 employees with capital of above 200 to 800 million Tanzanian shelling (URT, 2002). In same east Africa Kenya category differs by far more due its higher value of shillings around the region. Nigeria with the introduction of National policy on MSMEs has iron-out the definition as what indicates small and medium enterprises (SMEs) on reflecting develop economy in which the concept adopts and classified base on two criteria, employment and asset which excludes land and buildings.

\subsubsection{SMEs Growth and Development}

SMEs concept has angle of benefits to the economic growth and development of develop and under developing countries are being measured in scale through the outcome of many variable of SMEs from it output levels, cost of living as well as it standards of living to get to the Gross domestic product (GDP). Therefore, SMEs across those countries has shown tremendous achievement that leads to those countries growth and development that they do talked about. For instance in Japan it has recorded 53.3\%, Malaysia recorded 4.7.3\% and china has $60.0 \%$ the total GDP (Gross domestic product) for china alone it has over 10 million SMEs in which conclusively contributed about $60 \%$ of its total output level. Germany has $48 \%$, USA with $45 \%$ in which to say SMEs in the states generates above half of its national domestic products. India with its population growth like Nigeria its MSME sector has about $45 \%$ of output in manufacturing sector alone. Indeed SMEs has a say when it comes to growth and development OECD (2004) indicates that 90\% of the Small and medium enterprises in its member countries are SMEs. Also on same line OECD (2010) Reported that 99\% of SMEs do add up about 50-75\% qualitative value addition in difference area of the economy of its member countries. Onugu,(2005) states that SMEs has perform significantly in the develop economies over the years in countries like United kingdom, USA and Germany and also an undeveloped economy like India.

Kenyan economy for example the sector contributes to the national objective of creating opportunities, generating income and providing a source of livelihoods for the majority of low income households in the country accounting for 12-14\% of GDP( Konbo et. Al., 2003). In Nigeria it has not performed creditably well and they have not played expected significant role in economic growth and development on the reflected years due political landscape changes, corruption, military coups and conflicts. Ariyo,(2011) established that few year ago SMEs in Nigeria contributed about $50 \%$ of all industrial output along the way total reliance on oil, corruption and crisis affects the sector badly. 


\subsubsection{SMEs Challenges}

Small and medium enterprises are bound with challenges across the globe with one or more problems of the other. Onugu, (2005) stated that these challenges ranges from poor power supply, corruption, regulations policies and infrastructures among other. Funsho, (2015) indicates that lack of stability and frequent changes in policy framework. However, these lines of challenges highlighted by the previous researches were obvious to SMEs in Nigeria in particular.

Onugu (2010) asserts that the major challenges facing SMEs include; insufficient capital, lack of focus, inadequate market research, overconcentration on one or two markets for finished products, lack of succession plan, inexperience, lack of proper book keeping, lack of proper records or lack of any records at all, inability to separate business and family or personal finances, lack of business strategy, inability to distinguish between revenue and profit, inability to procure the right plant and machinery, inability to engage or employ the right caliber of staff, painlessness, cut-throat competition, lack of official patronage of locally produced goods and services, dumping of foreign goods and over-concentration of decision making on one (key) person, usually the owner. Other challenges which SMEs face in Nigeria include irregular power supply and other infrastructural inadequacies. unfavourable fiscal policies, multiple taxes, levies and rates, fuel crises or shortage, policy inconsistencies, reversals and shocks, uneasy access to funding, poor policy implementation, restricted market access, raw materials sourcing problems, competition with cheaper imported products, problems of inter-sectorial linkages given that most large scale firms source some of their raw material outside instead of sub-contracting to SMEs, insecurity of people and property, fragile ownership base, lack of requisite skill and experience, thin management, unfavourable monetary policies, lack of preservation, processing and storage technology and facilities, lack of entrepreneurial spirit, poor capital structuring as well as poor management of financial, human and other resources. Osoba (1987) and Innag and Ukpong (1993) opine that financial institutions classify loans disbursed to small and medium scale enterprises as "high risked loans".

\subsubsection{SMEs and government policies}

Every business or start-up was e-ray by the government official ranging from local, state and federal level in Nigeria. Therefore, for SMEs to operate it's a perquisite to follow the due process from registration by ministry of commerce and industry at state level and the various agencies responsible for registration. However, it is an organized due process for the SMEs but unfortunately, those SMEs were subjected to other regulation on taxes, operation license and other business regulation exercises. Harry, (2011) stated that these enforcement regulations normally used are too rigid to SMEs development and trading volumes. Creation of top government policies on SMEs affects their trading (Sattie, 2006) .By doing such it hinders the growth and development of SMEs.

\section{Theoretical framework}

Rashid (2011) argued that there are various theories that can be used to explain small and medium scale enterprises and also the issues that arise as a result of these conventions. Various theories have been employed in explaining these small and medium scale enterprises conventions; these theories include the contingency theory and stewardship theory. These theories are explained below.

\subsection{The Contingency theory}

Contingency theory provides a vital approach for models and also predicts suggested outcomes. The concept is very similar to the one normally uses in direct practice aspect in management and other areas of knowledge as well as direct services for example military or disaster interventions for displaced people. A contingency simply reflects a joint relationship (union) between phenomena or situational activity Contingency theory indicates a transitional level between variables, but times contingency reflects "condition". Contingency theory assisted in trying to attempt centralized decisions making units by strategizing and implementing to analyze, Contingency theory set goals or objectives in non favorable situation or anticipation of such related needs. The theory indicates a clear open relationship bond and it can be incorporate between problem and solution at hand for example;

$$
\text { Government policy } \longrightarrow \text { SMEs } \longrightarrow \text { Development }
$$


The above simple sequence indicates a transitional level between variables, but times contingency reflects "condition". Therefore, on this study contingency theory assisted in trying to attempt centralized decisions making units by strategizing and implementing to analyze situations as well as pointing out variables necessary needed for that very concerned contextual challenges. Contingency theory is use to set goals or objectives in non favorable situation or anticipation of such related needs.

\subsection{Stewardship Theory}

In the stewardship, managers are assumed to be good stewards of the corporations and diligently work to attain high levels of corporate profit and shareholders returns (Donaldson and Davis 1994, hereafter referred to as (D \& D). Their arguments support the investment of business schools in the development of management skills and knowledge. It also reinforces the social and professional kudos of being a manager. Whereas agency theorists view executives and directors as self-serving and opportunistic, stewardship theorists, reject agency assumptions, suggesting that directors frequently have interests that are consistent with those of shareholders

\subsection{The Empirical review}

Several studies were conducted on SMEs challenges, problem and prospects in relation to growth and development. However, these studies pointed out several factors and key variables to identify those obstacles SMEs faced. For instance Robu, (2014) conducted a study on the dynamics and importance of SMEs in economy in Romania. The study pointed out the key impact of SMEs to the economy but centrally silent the key problem SMEs are facing toward the key important factor highlighted. Eniola, (2014) study on the role of SMEs and performance in Nigeria. Conclusively, the study pointed out the impact of growth, development and provision of employment, but the study failed to explained the key factors that affects the growth and development especially corruption which is obvious in Nigeria. On same vain Ibrahim et al, (2015) conducted a study on the evaluation of performance of SMEs development in Nigeria. The study cut across the key SMEs variables but was not been able to capture the general context of Nigerian SMEs challenges. On same vain this study is so keen and motivated to established evidence on these challenges ascertain especially, in a context of current phenomena SMEs face in Bauchi state. Finally, the study will utilize the element of contingency theory as these SMEs require sound institutional framework to mitigate these challenges Agwu (2014), also researched on other challenges faced by SMEs in Nigeria which includes the lack of finance by government and financial institutions, poor marketing system resulting in the low sales of output, ban on importation of raw materials for those whose resources are imported, lack of managerial ability on the part of the entrepreneur, high cost of production, the continual increase in prices of goods and services, lack of adequate production machines, inability to distinguish target markets, high cost of labour, competing with cheap imported products, high cost of advertisement in the media houses, high cost of factors of production such as land as well as lack of entrepreneurial skill. A research by Basil (2005) shows that lack of power supply and basic amenities like roads, water, internet facility etc. ranks the top challenges faced by SMEs in Nigeria. This is because these amenities aid SME operations in the area of reducing costs, production and marketing. Olayide (1970) said that the major constraints which hindered development of the SMEs includes inadequate infrastructure and restrictive industrial policy of the government. Similarly, Stolpher (1970) argued that a major problem facing the Nigerian SMEs is the formulation and pursuing of policies which are supposed to make the economy more productive and flexible.

\section{Methodology}

Research Design: The study adopted a descriptive research design. Descriptive research design was employed because is an efficient way of gathering data to help address a research questions and one can collect unbiased data and develop sensible decision based on analyzed results (Van de van, 2007).

Sampling Method and Sample Size: Purposive random sampling technique was used to select two management staff each from the sixty (60) selected manufacturing companies in Nigeria totaling one hundred and twenty (120) respondents as a sample size for the study.

Data Collection Instruments: A structured questionnaire was used to collect relevant information from the study's participants. 


\section{Data processing and analysis}

Data analysis is the process of data to make meaningful information (Saunders, Lewis \& Thornhill, 2009) defined data as mechanism for reducing and organizing data to produce findings that require interpretation by researcher. According to Hyndman (2008) data processing involves translating the answers on a questionnaire into a form that can be manipulated to produce statistics. This involves coding, editing, data entry, and monitoring the whole data processing procedure. Data collected was analyzed by editing, coding and categorizing with the use of statistical package for social sciences (SPSS) version 20.0-computer software.

Validity and Reliability of Research Instruments: The instruments used in this study were submitted to a panel of experts for validation. The panel carried out a content analysis of each of the questionnaires and eliminated items found to be irrelevant to the research problem. After necessary modifications, the panel of experts recommended the use of the instruments for the study. The scales were subjected to further item analysis as to determine their psychometric soundness as indicated in Table1 below:

Table 1. Summary of Results of the Measurement Instruments Validation

\begin{tabular}{|c|c|c|c|c|c|c|}
\hline Scale & No of Items & Meaning Bartlett & KMO & $\begin{array}{c}\text { Eigenvalue of the } \\
\text { principal } \\
\text { Component }\end{array}$ & $\begin{array}{c}\% \text { of the } \\
\text { variance }\end{array}$ & $\alpha$ of Cronbach \\
\hline $\begin{array}{c}\text { Government } \\
\text { policies } \\
\text { Questionnaire }\end{array}$ & 7 & $\begin{array}{c}\mathrm{p}=.000 \\
\text { (significant) }\end{array}$ & 0.810 & 3.679 & $75.49 \%$ & 0.81 \\
\hline
\end{tabular}

Source: Field Report, 2020.

From Table 1 above, factor loads of all the indicators are higher than 0.5 which shows that the questions highly explain the variance of their variables so we can say that the measurement model has high factor validity.

Method of Data Analysis: Mean was used to analyse data and criterion mean of 3 was used for interpretation of mean. Criterion mean of 3 was generated by adding the total assigned values of the responses and dividing by the total number of responses $(5+4+3+2+1=15 / 5=3)$. Thus any mean score up to 3 and above was interpreted as acceptable by respondents while 2.99 and below is adjudged rejected by the respondents. Regression Analysis was used to test the hypotheses.

\section{Regression Model}

$\mathrm{OP}=\alpha+\beta 1_{\mathrm{x} 1}+\mu$

Where the variables are defined as GD - Growth and development, $\mathrm{X}_{1}$ - Government policies, $\alpha$ - regression output(constant), $\mu$ - Error term.

\section{Results and Discussion}

\section{Effect of Government policies on SMEs growth and development}

Table 2. Distribution of respondents by effect of Government policies on growth and development

\begin{tabular}{|l|c|c|}
\hline \multicolumn{1}{|c|}{ Statement } & Mean & Rank \\
\hline $\begin{array}{l}\text { Government policies on incentives are adequate for the survival and development of small } \\
\text { medium scale enterprises }\end{array}$ & 4.01 & Accepted \\
\hline $\begin{array}{l}\text { Ban on importation for some foreign products is the right step for developing small and medium } \\
\text { scale enterprises }\end{array}$ & 3.98 & Accepted \\
\hline High interest rate has lead to low growth of SMEs & 3.76 & Accepted \\
\hline Government policies ont Aids has adversely affected the growth and development of SMEs & 3.65 & Accepted \\
\hline Government policies on raw materials has led the growth and development of SMEs & 4.12 & Accepted \\
\hline Harsh policies by the government has negatively affected the growth of SMEs & 4.15 & Accepted \\
\hline Lack of political stability has adversely affected the growth and development of SMEs & 4.09 & Accepted \\
\hline \multicolumn{1}{|c|}{ Grand mean } & 3.96 \\
\hline
\end{tabular}

Source: Field Report, 2020. 
In Table 2, the grand mean of 3.96 which is above the criterion mean of 3 shows that respondents agreed that government policies has significant effect on the growth and development of SMEs. Results also indicate that on average; the respondents agreed that challenges face by SMEs has enabled some enterprises to develop new products quickly remained competitive in the global market. Government policies is a major factor which has affected the growth of SMEs with mean values of 4.15, 4.12, 4.09, 4.01 and 3.98 respectively. This implies that government policies is an alternative paradigm to SMEs growth in a global competitive environment.

Table 3. Impact of government policies on SMEs growth and development

\begin{tabular}{|l|c|c|c|c|c|}
\hline Model & $\mathbf{R}$ & $\mathbf{R}^{\mathbf{2}}$ & ${\text { Adjusted } \mathbf{R}^{\mathbf{2}}}$ & \multicolumn{2}{|c|}{ Std error of the estimate } \\
\hline 1 & 0.761 & 0.579 & 0.490 & \multicolumn{2}{c|}{1.602} \\
\hline Explanatory variable & $\mathbf{B}$ & Std error & $\mathbf{t}$ - value & p- value & Remarks \\
\hline Constant & 21.450 & 0.875 & 28.510 & 0.000 & \\
\hline Government policies & 0.232 & 2.074 & 1.786 & 0.011 & $\mathrm{~S}$ \\
\hline
\end{tabular}

Source: Field Report, 2020.

Table 3 revealed that government policies $(\beta=0.26 ; \mathrm{t}=0.233 \mathrm{P}<.05)$ has positive and significant impact on SMEs growth and development. Result also indicated that government policies has 57.9\% influence on SMEs growth and development. This implies that the higher the government policies the higher the growth and development. The study is consistent with Vivian and Christopher (2015) and Akinbola, Ogunnaike and Ojo (2013) that government policies is a strong predictor of SMEs growth and development.

Therefore, the null hypothesis which states that government policies do not have an impact on SMEs growth and development is rejected, while the alternative is accepted.

\section{Conclusion and Recommendation}

This study examines the impact of government policies on the growth and development of SMEs in Bauchi state Nigeria.

The study reveals that government policies, are the major challenge that affects SMEs growth and development in the global competitive environment. The findings further show that this factor has a significant impact on SMEs growth and development.

The study also concludes that government policies significantly affect the growth of SMEs in Bauchi State Nigeria. Further, the study concludes that government policies influence the growth of SMEs in Nigeria positively and significantly.

Finally, the study concludes that there is a positive relationship between government policies and SMEs in Bauchi State.

\section{Recommendations}

Based on the Findings of the Study, the Following Recommendations are made:

- $\quad$ The study therefore recommends that, the government of Bauchi State should increase awareness on government regulations for business owners.

- $\quad$ The Bauchi State government should make sure SMEs owners should stream line rules and regulations governing the general operation of SMEs in Bauchi State.

- The study recommends that management of SMEs should adopt good strategic in order to overcome these challenges.

Funding: self-funded.

Authors' Contribution: conceptualization: Yakubu Yahaya, Umar Ayuba Dutse, Sule Bello; data curation: Yakubu Yahaya, Umar Ayuba Dutse, Sule Bello; formal analysis: Yakubu Yahaya, Umar Ayuba Dutse, Sule Bello; funding acquisition: Yakubu Yahaya, Umar Ayuba Dutse, Sule Bello; investigation: Yakubu Yahaya, Umar 
Ayuba Dutse, Sule Bello; methodology: Yakubu Yahaya, Umar Ayuba Dutse, Sule Bello; project administration: Yakubu Yahaya, Umar Ayuba Dutse, Sule Bello; resources: Yakubu Yahaya, Umar Ayuba Dutse, Sule Bello; software: Yakubu Yahaya, Umar Ayuba Dutse, Sule Bello; supervision: Yakubu Yahaya, Umar Ayuba Dutse, Sule Bello; validation: Yakubu Yahaya, Umar Ayuba Dutse, Sule Bello; visualization: Yakubu Yahaya, Umar Ayuba Dutse, Sule Bello; writing - original draft: Yakubu Yahaya, Umar Ayuba Dutse, Sule Bello; writingreview and editing: Yakubu Yahaya, Umar Ayuba Dutse, Sule Bello.

\section{References}

1. Anthony, E. and Harry, E. (2015) Government policy and Performance of SMEs. https://booktree.ng/wpcontent/uploads/2019/01/Government_Policy_and_Performance_of_Small_and_Medium_Business_Manag ement.pdf

2. Anthony A. Eniola (2015). Government Policy and Performance of Small and Medium Business Management

3. Busin ess management: International journal of academic Research in Business \& Social sciences, 5(2), [CrossRef].

4. APA Referencing style Guide (2014). Retrieved from University of Western Sydney Library. Available at: [Link].

5. Akanbe, B., Jegede, C. \& Osetimehin, K. (2012). An Evaluation of the Challenges and Prospects of Micro and Small Scale Enterprises Development in Nigeria. American International Journal of Contemporary Research, 2(4). Available at: [Google Scholar], [Link].

6. Akeredole-Ale, E.O. (1975). The Under Development of Indigenous Entrepreneurship in Nigeria, (pp. 106122). University Press, Ibadan. Available at: [Google Scholar], [Link].

7. Brockhous, D.E. (1980). The effect of Job Dissatisfaction on the Decision to Small Business, Journal of Small Business Management, 8(1), 20-25. Available at: [Link].

8. Brown, H.N. and Longenecker, J.G. (1971). Small Business Management, South-West (pp 8-113) Publishing Co, Ohio. Available at: [Link].

9. Clercq, D. D., Dimov, D. \& Thongpapanl, N. (2010). The Moderating Impact of Internal Social Exchange Processes on the Entrepreneurial Orientation - Performance Relationship. Journal of Business Venturing, 25(1), 87-103. Available at: [Google Scholar], [Link].

10. Covin, J.G. \& Slevin, D.P. (1991). A Conceptual Model of Entrepreneurship as Firm Behaviour, Entrepreneurship Theory and Practice, 15(1), pp. 7-24. Available at: [Google Scholar], [Link].

11. Enilie, C. and Knifack, R. (2011). Regulations, SMEs Performance and growth in Cameroon Manufacturing Retail sector: Trust investment climate \& Business Environment Research Fund. Available at: [Link].

12. Essien, O.E. (2001). The Role of Development Finance Institutions in the Financing of Small Scale Industries. CBN Bullion, 25(3). Available at: [Google Scholar].

13. Funsho, F. (2015) Issues, Challenges and prospects of SMEs in Africa: A Survey of SMEs in Nigeria. Available at: [Google Scholar], [Link].

14. Zahid Laghari, Afreen Ali (2014) Grand Canyon University American Psychological Association (6 ${ }^{\text {thed.) }}$ Style Guide for Writing. Available at: [Link].

15. Helle Neergaard, John P. Ulhøi (Eds). (2007). Handbook of qualitative Research Methods. In Entrepreneurship MPG Book ltd. Bodwin, Corwall. Available at: [Google Scholar], [Link].

16. Pillania, K.R. (2008). Strategic Issues in Knowledge Management in Small and Medium Enterprises. Knowledge Management Research \& Practice, 6(4), 334-338. [CrossRef]. 